\title{
Water structuring device for the quality improvement of aromatic plants
}

\author{
Domenico Prisa * \\ CREA Research Centre for Vegetable and Ornamental Crops, Council for Agricultural Research and Economics, Via dei \\ Fiori 8, 51012 Pescia, PT, Italy.
}

Publication history: Received on 20 August 2020; revised on 01 September 2020; accepted on 03 September 2020

Article DOI: https://doi.org/10.30574/gscbps.2020.12.3.0270

\begin{abstract}
The paper presents the results of research aimed at improving the growth of aromatic plants and stimulating microbial communities in the rhizosphere of two test plants (Lavender and Rosemary), using a water structuring device (Alchewat). The experiments, started in November 2019, were conducted in the greenhouses of CREA-OF in Pescia (PT). The experimental groups were: i) group without structured water, irrigated with water and substrate previously fertilized; ii) group with structured water, irrigated with water and substrate previously fertilized. The test showed a significant improvement in the agronomic parameters analyzed in Lavender and Rosemary plants treated with structured water. In particular, all plants treated with structured water showed a significant increase in plant height, vegetative and roots weight, total flowers biomass and total microbial count. In addition, there was a significant reduction in Lavender of the number of plants dried in structured water treatment and a positive trend in Rosemary, but not significant. The results of this experiment are in accordance with literature and field observation data that report a beneficial effect of structured water on plant growth, health, quantity and quality of yields. Also very interesting is the increase in the substrate of the theses treated with structured water of the number of useful microorganisms, which are probably supporters of the improvement of plant growth. The presence of microorganisms in the substrate can also affect the biotic and abiotic stress resistance of plants. These aspects consequently become very interesting for the grower who can reduce the use of water and fertilizers and increase the quality of the plants by using alternative techniques.
\end{abstract}

Keywords: Structured water; Biostimulant; Liquid crystal; Microorganisms; Hydrophilic

\section{Introduction}

The characteristic of structured water is to position the individual molecules that compose it in a precise order, this positioning generates a structure that allows a greater conservation of information. To understand what the ordered structure of water is you can see it in snowflakes: observing under a microscope the shape of the small ice crystals you can see how the arrangement of the water molecules has generated the shape of perfectly dimensioned and harmonious 6-pointed crystals, another characteristic that is noticeable is the particular transparency of the ice. The water present in the human body, as well as the living, natural water from an Alpine spring, have the same structure. Structured water has a higher energy and scientists have been able to establish a direct correlation between the order level of the water structure and human health [1]. As the water, which contains these ordered structures, has a higher energy, some scientists have been able to establish a direct correlation between the degree of order in water and human health. For this reason, structured water has become an interesting and widely discussed topic in many books that deal in detail with the way water is affected by external influences. The authors describe and explain exactly why and how structured water can have such a positive effect on the human body and what methods can be adopted for its structuring. Scientific

\footnotetext{
${ }^{*}$ Corresponding author: Domenico Prisa

CREA Research Centre for Vegetable and Ornamental Crops, Council for Agricultural Research and Economics, Via dei Fiori 8, 51012 Pescia, PT, Italy.
} 
experiments in recent years confirm that many materials have a memory that allows them to transmit information. Using the most suitable materials for storing information, for a more or less long period, they can be used to transfer the stored information to other materials or living beings. Telemental broadband spiral antennas are able to influence the humidity present in the soil by receiving and transmitting the electrostatic and electromagnetic fields present in nature through helical antennas specially made of silver-copper metal alloys [2]. The first studies concerning the structure of water date back to a century ago. The tetrahedral structure of the hydrogen bond was initially suggested through X-ray analysis in 1938 and remained for almost eighty years in people's disbelief [2-3]. An absolute pioneer in the field of structured water is Prof. Gerald Pollack of the University of Washington, who defined the fourth phase of water, also referred to as structured water. Through the use of nuclear magnetic resonance spectroscopy (NMR), it is possible to see this hexagonal structure and there are several scientific publications in research journals on this topic $[4,5]$. The increased hydration of the cell walls consequently leads to a higher yield in the plants. Therefore, structured water is highly applicable in agriculture. The density of structured water is higher than that of ordinary water, suspended microspheres are excluded on the basis of this phenomenon, it has been named as exclusion zone [6]. Furthermore, it has been observed that the electrical potential down to $-200 \mathrm{mV}$ develops beyond the boundary of the exclusion zone and outside this region (negative exclusion zone). This potential is generated by the dissociation of water molecules into negative ions (OH-) and protons as it is structured [7]. This important finding implies that water itself can affect the growth and bioactivity of live beings. Structured water is a molecular arrangement of water molecules that exists when water is near hydrophilic (water loving) surfaces. Much like ice, water molecules join together in hexagonally structured single layer sheets. As the hexagonal layers grow, protons are ejected into the nearby water [1]. Producers of structured water units recommend the use of structured water for many agricultural applications because it contains no energetic toxins. It brings forward with high oxygenation state, increases the energy, regulates and balances the soil minerals. Through the use of structured water various crops such as strawberry, tangerine, sprouts, lemon and grapes grew faster and healthy, plants matures sooner, more tasty yields, and the time of staying fresh (shelf life) increased [8]. Generally, benefits gained from using structured water include: up to $100 \%$ increase fruit/grain/vegetables; up to $60 \%$ reduction in water usage; up to $100 \%$ reduction of chemical use; improve pest, mould, algae control; healthier crops, birds, cows; resistance to extreme temperature; improve soil condition; enhances taste, texture and shelf life of fruit and vegetables [9]. Research carried out in University of Colorado gained new aspects of obtaining and practical use of structured water technology in large scale agriculture as a further promise for water conservation and increased yields and its quality [10].

The paper presents the results of research aimed at improving the growth of aromatic plants and stimulating microbial communities in the rhizosphere of two test plants (Lavender and Rosemary), using a water structuring device (Alchewat).

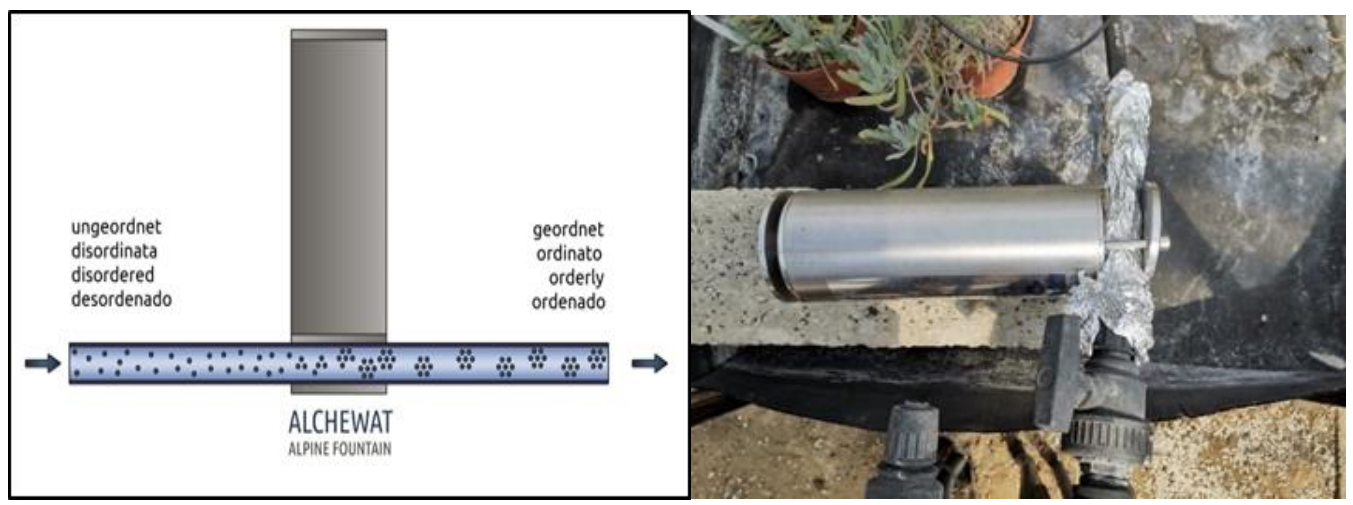

Figure 1 - Detail of Alchewat's operating mechanism and its use in greenhouse cultivation

\section{Material and methods}

\subsection{Greenhouse experiment and growing conditions}

The experiments, started in November 2019, were conducted in the greenhouses of CREA-OF in Pescia (Pt), Tuscany, Italy $\left(43^{\circ} 54^{\prime} \mathrm{N} 10^{\circ} 41^{\prime} \mathrm{E}\right)$ on Lavander and Rosemary.

The plants were placed in $\varnothing 16 \mathrm{~cm}$ pots; 30 plants per thesis, divided into 3 replicas of 10 plants each. All plants were fertilized with a controlled release fertilizer ( $2 \mathrm{~kg} \mathrm{~m}^{-3}$ Osmocote Proß, 6 months with $190 \mathrm{~g} / \mathrm{kg} \mathrm{N}, 39 \mathrm{~g} / \mathrm{kg} \mathrm{P,} 83$ g/kg K) mixed with the growing medium before transplanting. 
The experimental groups were:

- Group without structured water (CT) (peat 70\% + pumice 30\%), irrigated with water and substrate previously fertilized;

- Group with structured water (SW) (peat 70\% + pumice 30\%), irrigated with water and substrate previously fertilized.

For structuring the water, Alchewat alpine fountain was used, according to the manufacturer, this device vitalizes and improves the water through biomagnetic induction processes and with the help of transmaterial catalysts. The device forwards a modulating structured frequency to the water flowing in the pipe. This changes the molecular behavior of the water and brings it to a level similar to pure spring water. The device forwards a modulating structured frequency to the water flowing in the pipe. This changes the molecular behavior of the water and brings it to a level similar to pure spring water. The device is mounted on the irrigation pipe and consists of a mix of minerals, precious metal alloys, diamagnetic transition metals and alpine source water. The whole process of water restructuring is carried out in a manner absolutely ecological, requires neither maintenance nor any chemical products and does not need electricity.The plants were watered 2 times a day and grown for 8 months. The plants were irrigated with drip irrigation. The irrigation was activated by a timer whose program was adjusted weekly according to climatic conditions and the fraction of leaching. On June 15, 2020, plant height, vegetative weight, roots weight, total flowers biomass, number of dried plants, microbial count in the growing medium have been evaluated. Microbiological analysis of samples collected from rhizosphere were performed by plating soil decimal diluitions on specific solid culture media: Nutrient agar for heterotrophic bacteria and Czapek for fungi. After incubation, the developed colonies were counted and the densities of microbial structures were reported to gram of dry soil $[11,12]$.

\subsection{Statistics}

The experiment was carried out in a randomized complete block design. Collected data were analysed by one-way ANOVA, using GLM univariate procedure, to assess significant $(P \leq 0.05,0.01$ and 0.001$)$ differences among treatments. Mean values were then separated by LSD multiple-range test $(P=0.05)$. Statistics and graphics were supported by the programs Costat (version 6.451) and Excel (Office 2010).

\section{Results}

\subsection{Plant growth}

The test showed a significant improvement in the agronomic parameters analyzed in lavender and rosemary plants treated with structured water. In particular, all plants treated with structured water showed a significant increase in plant height, vegetative weight, root weight, total flower biomass and total microbial count. In addition, there was a significant reduction in lavender, the number of plants dried in structured water treatment and a positive trend in rosemary, but not significant

Table 1 - Evaluation of structured water on agronomic characters on plants of Lavander and microbial count in the different treatments.

\begin{tabular}{|c|c|c|c|c|c|c|}
\hline Groups & $\begin{array}{c}\text { Plant } \\
\text { height } \\
\text { (cm/plant) }\end{array}$ & $\begin{array}{c}\text { Vegetative } \\
\text { weight } \\
\text { (g/plant) }\end{array}$ & $\begin{array}{c}\text { Roots } \\
\text { weight } \\
\text { (g/plant) }\end{array}$ & $\begin{array}{c}\text { Total flowers } \\
\text { biomass } \\
\text { (g/plant) }\end{array}$ & $\begin{array}{c}\text { Number dried } \\
\text { plants } \\
\left(n^{\circ}\right) \\
\end{array}$ & $\begin{array}{c}\text { Microbial } \\
\text { Count } \\
\text { (cfu x g-1 ds) }\end{array}$ \\
\hline CT & $48,33^{\mathrm{b}}$ & $57,06^{\mathrm{b}}$ & $43,55^{b}$ & $25,00^{\mathrm{b}}$ & $2,20^{a}$ & $22,1 \times 10^{3}$ \\
\hline SW & 57,00 a & $63,13^{a}$ & $49,42^{\text {a }}$ & $30,45^{\text {a }}$ & $0,40^{\mathrm{b}}$ & $28,4 \times 10^{3}$ \\
\hline ANOVA & $* * *$ & $* * *$ & $* * *$ & $* * *$ & $* *$ & - \\
\hline
\end{tabular}

One-way ANOVA; n.s. - non significant; ***,*** - significant at $\mathrm{P} \leq 0.05,0.01$ and 0.001 , respectively; different letters for the same element indicate significant differences according to Tukey's (HSD) multiple-range test $(\mathrm{P}=0.05)$; Legend: $(\mathrm{CT})$ control; (SW) structured water

In Lavender (Table 1), the treatment with structured water significantly improved the height of the plant, $57.00 \mathrm{~cm}$ (SW) compared to $48.33 \mathrm{~cm}$ of the untreated control. There was a significant increase in vegetative weight in (SW), 63.13 g compared to 57.06 in (CT) (Figure 2A) and root weight $49.42 \mathrm{~g}$ (SW) compared to $43.55 \mathrm{~g}$ in the untreated control (Figure 3A). There is also a significant increase in the total biomass of the flowers in the thesis treated with 
structured water (SW), $30.45 \mathrm{~g}$ compared to $25.00 \mathrm{~g}$ of the control (Figure 2C). The test also showed a significant reduction of dried plants in the thesis (SW), 0.40 compared to 2.20 of (CT). Interesting aspect is the increase of microorganisms in the substrate treated with structured water (SW), $28.4 \times 10^{3} \mathrm{cfu} \mathrm{x} \mathrm{g}^{-1} \mathrm{ds}$, compared to $22.1 \times 10^{3} \mathrm{cfu}$ $\mathrm{x} \mathrm{g}^{-1} \mathrm{ds}$ in the control.

In Rosemary (Table 2), the treatment with structured water significantly improved, also on this species, the height of the plant, $63.34 \mathrm{~cm}(\mathrm{SW})$ compared to $56.48 \mathrm{~cm}$ of the untreated control.

Table 2 - Evaluation of structured water on agronomic characters on plants of Rosemery and microbial count in the different treatments.

\begin{tabular}{|c|c|c|c|c|c|c|}
\hline Groups & $\begin{array}{c}\text { Plant } \\
\text { height } \\
\text { (cm/plant) }\end{array}$ & $\begin{array}{c}\text { Vegetative } \\
\text { weight } \\
\text { (g/plant) }\end{array}$ & $\begin{array}{c}\text { Roots } \\
\text { weight } \\
\text { (g/plant) }\end{array}$ & $\begin{array}{c}\text { Total flowers } \\
\text { biomass } \\
\text { (g/plant) }\end{array}$ & $\begin{array}{c}\text { Number } \\
\text { dried plants } \\
\text { (n } \mathbf{n}^{\circ}\end{array}$ & $\begin{array}{c}\text { Microbial } \\
\text { Count } \\
\text { (cfu x g } \mathbf{~ g}^{-1} \mathbf{d s} \text { ) }\end{array}$ \\
\hline CT & $56,48^{\mathrm{b}}$ & $48,60^{\mathrm{b}}$ & $38,90^{\mathrm{b}}$ & $14,91^{\mathrm{b}}$ & $0,80^{\mathrm{a}}$ & $25,6 \times 10^{3}$ \\
\hline SW & $63,34^{\mathrm{a}}$ & $54,68^{\mathrm{a}}$ & $42,98^{\mathrm{a}}$ & $16,33^{\mathrm{a}}$ & $0,20^{\mathrm{a}}$ & $29,8 \times 10^{3}$ \\
\hline ANOVA & $* * *$ & $* * *$ & $* * *$ & $* *$ & $\mathrm{~ns}$ & - \\
\hline
\end{tabular}

One-way ANOVA; n.s. - non significant; ${ }^{* * *}, * * *$ - significant at $\mathrm{P} \leq 0.05,0.01$ and 0.001 , respectively; different letters for the same element indicate significant differences according to Tukey's (HSD) multiple-range test ( $\mathrm{P}=0.05)$; Legend: $(\mathrm{CT})$ control; (SW) structured water

There was also a significant increase in vegetative weight in (SW), $54.68 \mathrm{~g}$ compared to 48.60 in (CT) (Figure 2B) and root weight $42.98 \mathrm{~g}$ (SW) compared to $38.90 \mathrm{~g}$ in the untreated control (Figure 3B). The test showed a significant increase of the total biomass of the flowers in the thesis treated with structured water (SW), 16.33 g compared to 14.91 $\mathrm{g}$ of the control. As for lavender also on rosemary there was a reduction of the dried plants in the thesis (SW), 0.20 compared to 0.80 of (CT). Particular and interesting is the fact that even on rosemary there is an increase of microorganisms in the substrate treated with structured water (SW), $29.8 \times 10^{3} \mathrm{cfu} \times \mathrm{g}^{-1} \mathrm{ds}$, against $25.6 \times 10^{3} \mathrm{cfu} \times \mathrm{g}^{-1}$ ds of the control.

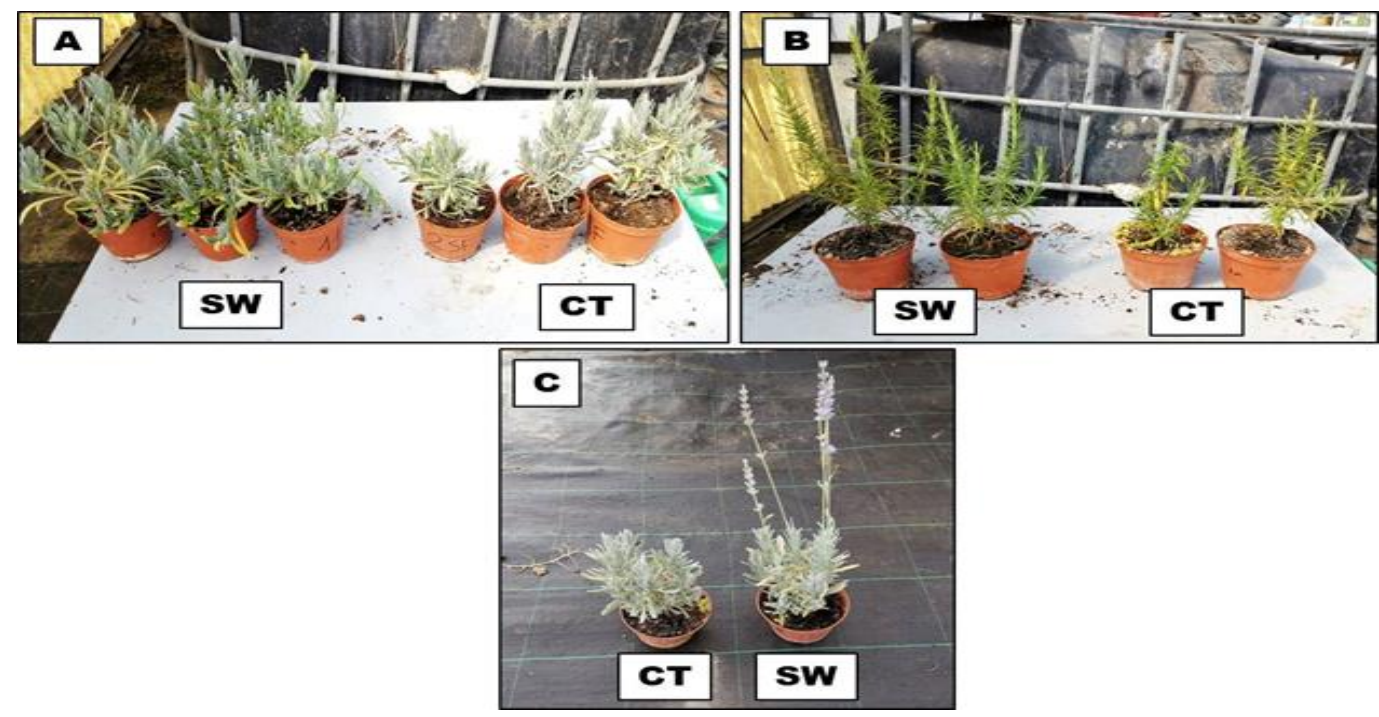

Figure 2 - Effect of structured water on vegetative growth of Lavander (A), Rosemary (B) and flowers of Lavander (C). Legend: (CT) control; (SW) structured water 

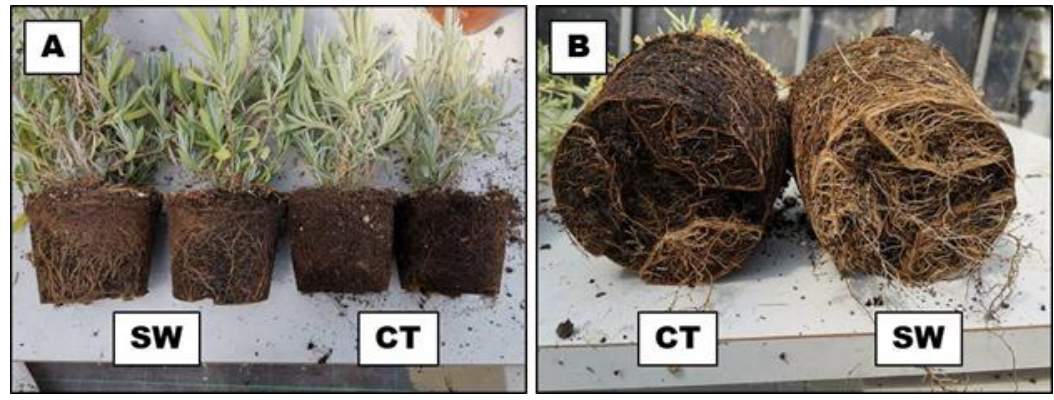

Figure 3 - Effect of structured water on roots growth of Lavander (A) and Rosemary (B) Legend: (CT) control; (SW) structured water

\section{Discussion}

Structured water is characterized by a particular molecular arrangement of water molecules that is formed when the water is close to hydrophilic (water-loving) surfaces. As in ice, the water molecules unite in monolayer sheets with a hexagonal structure, growing the layers, the protons are expelled into the adjacent water. There are several properties of structured water in general, e.g.: i) Inhibition of deposition/fouling of dissolved substances (e.g. limestone), which is very useful for example in saving boilers and connecting pipes from fouling; ii) low surface tension and increased wetting properties; iii) pH is slightly above 7, which allows it to be assimilated into body fluids; iv) neutralizes the effect of acid chlorine; v) 'structured water strengthens the hydrogen bond [13].

In agriculture, structured water can provide the following advantages: i) increased soil health with improved plant growth; ii) increased soil efficiency in supplying plants with nutrients; iii) increased plant capacity to absorb nutrients from the soil; iv) increased soil water retention with reduced irrigation turnover (20-50\%); v) improved plant quality and shelf-life; vi) increased vegetative quality of plants and reduction of diseases; vii) increased crop quality and quantity; viii) improved flower colour intensity; ix) increased antioxidant properties of water. Water itself may be an active constituent in cell biology, like many other cellular molecules $[8,14]$. The use of structured water can result in increased crop yields in winter wheat (28\%), cucumber (32\%) and tomato (32\%). It can also increase milk production and fertility in cattle, meat and egg production in poultry. With both qualitative and quantitative improvements in yield [8]. The results of this experiment are in accordance with literature and field observation data that report a beneficial effect of structured water on plant growth, health, quantity and quality of yields [15]. In fact, the use of structured water on lavender and rosemary promotes plant height, vegetative and root development, total biomass of flowers, reduction of dried plants and a very interesting aspect is the increase in microbial count of treated substrates. Experiments conducted by private and public farmers in America have also shown that it is possible to reduce water consumption by 20-30\% for the cultivation of important fruit species while increasing shelf life and nutrient density [12].

\section{Conclusion}

The experimental results confirm that structured water shows plant growth-promoting effects, particularly on the growth of lavender and rosemary. There were significant increases in plant height, vegetative and root biomass, total flower weight and a significant reduction in the number of dried plants. Also very interesting is the increase in the substrate of the theses treated with structured water of the number of useful microorganisms, which are probably supporters of the improvement of plant growth. The presence of microorganisms in the substrate can also affect the biotic and abiotic stress resistance of plants $[16,17,18,19,20]$. These aspects consequently become very interesting for the grower who can reduce the use of water and fertilisers and increase the quality of the plants by using alternative techniques.

\section{Compliance with ethical standards}

\section{Acknowledgments}

The research is part of the project "Structured water for agriculture", in line with the "Micronaturale" project: innovative techniques with low environmental impact for the plants growth and protection. 


\section{Disclosure of conflict of interest}

The author declares no conflict of interest.

\section{References}

[1] Abraham A. (2014). Structured water produced by the structured water unit eliminates staph Bacteria for raw diary.

[2] Zheng JM, Chin WC, Khijniak E, Khijniak E and Pollack GH. (2006) Advances in Colloid and Interface Science, 127(1), 19-27.

[3] Morgan J. (1938). The Journal of Chemical Physics, 6(11), 666.

[4] Chara O, Andres N, McCarthy and Grigera JR. (2011). Physics Letters, 572-576.

[5] Tiezzi E. (2013) Ann Chim, 5.

[6] Zheng JM, Chin WC, Khijniak E, Khijniak E and Pollack GH. (2006). Advances in Colloid and Interface Science, 127(1), 19-27.

[7] Seong GH, Lee HS, Lee BC and Bahng GW. (2017) International Journal of Cell Biology, 75-79.

[8] Husain SM and Abbas H. (2007) Institute of horticultural sciences, university of Agriculture, Fasilabad, 38-42.

[9] Sharma A, Toso D, Kung K, Banhg G and Pollak GH. (2017). Quelby®-Induced enhancement of exclusion zone buildup and seed germination. Advances in material science and engineering, 1-10.

[10] Ptok F. (2014). Alternative irrigation methods: structured water in the context of a growing global food crisis due to water shortages. Undergraduate Honors Theses. 182.

[11] Papacostea P. (1976). Biologia Solului (Soil Biology). Bucharest, RO: Scientific and Encyclopaedic Publishing House.

[12] Enache F, Matei S, Matei GM, Jerca IO and Draghici EM. (2019). Stimulation of plant growth and rhizosphere microbial communities by treatments with structured water. Scientific papers, Series B, Horticulture, Vol. LXIII, $\mathrm{N}^{\circ} 1$.

[13] Pollack GH. (2013). Seattle, WA: Ebner \& Sons.

[14] Pallavi HM, Varun N, Karthi KP and Manoj R. (2017). Navsari Agricultural University, Gujarat.

[15] Dubey PK, Neethu TM, Kaswala AR. (2018). Structured water: an exciting new field in water science. International journal of Agricultural science, 10(11), 6346-6347.

[16] Prisa D. (2019). Effect of chabazitic-zeolites and effective microorganisms on growth and chemical composition of Aloe barbadensis Miller and Aloe arborescens Miller. International Journal of Agricultural Research, Sustainability, and Food Sufficiency (IJARSFS), 6(01), 315-321.

[17] Prisa D. (2019). Effective microorganisms for germination and root growth in Kalanchoe daigremontiana. World Journal of Advanced Research and Reviews, 3(3), 047-053.

[18] Prisa D. (2019). Trichoderma harzianum: biocontrol to Rhizoctonia solani and biostimulation in Pachyphytum oviferum and Crassula falcata. World Journal of Advanced Research and Reviews, 3(3), 11-18.

[19] Prisa D. (2020). Plant growth promoting Rhizobacteria: Increase of vegetative and roots biomass in Portulacaria afra. GSC Advanced Research and Reviews, 2(2), 001-007.

[20] Prisa D. (2020). Improving Quality of Crocus Sativus Through the Use of Bacillus Subtilis, International Journal of Scientific Research in Multidisciplinary Studies, 6(2), 9-15. 


\section{Author's short biography}

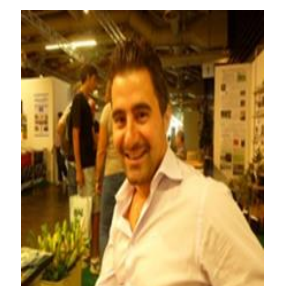

Dr. Domenico Prisa is Doctor of Philosophy - PhD, Crop Science Production (S.Anna-School of advances studies). Master of Science (MSc), Plant and Microbial Biotechnology (Pisa University). $\mathrm{He}$ is currently researcher at Council for Agricultural Research and Economics (CREA) Landscaping Plants and Nursery Research Unit in Pescia (PT). Activities in ornamental plants and horticulture, with particular reference to the study of microorganisms and biostimulants on succulent plants and cacti. Speaker at several national and international conferences in floriculture, sustainable agriculture, innovative substrates and biostimulants, microbiology and beekeeping. His skills comprise biotechnologies and innovative crop techniques. 